\title{
Xylanase and $\beta$-Xylosidase Production by Aspergillus ochraceus: New Perspectives for the Application of Wheat Straw Autohydrolysis Liquor
}

\author{
Michele Michelin • Maria de Lourdes T. M. Polizeli • \\ Denise S. Ruzene • Daniel P. Silva • António A. Vicente • \\ João A. Jorge • Héctor F. Terenzi • José A. Teixeira
}

Received: 31 May 2011 / Accepted: 20 October 2011/

Published online: 10 November 2011

(C) Springer Science+Business Media, LLC 2011

\begin{abstract}
The xylanase biosynthesis is induced by its substrate-xylan. The high xylan content in some wastes such as wheat residues (wheat bran and wheat straw) makes them accessible and cheap sources of inducers to be mainly applied in great volumes of fermentation, such as those of industrial bioreactors. Thus, in this work, the main proposal was incorporated in the nutrient medium wheat straw particles decomposed to soluble compounds (liquor) through treatment of lignocellulosic materials in autohydrolysis process, as a strategy to increase and undervalue xylanase production by Aspergillus ochraceus. The wheat straw autohydrolysis liquor produced in several conditions was used as a sole carbon source or with wheat bran. The best conditions for xylanase and $\beta$ xylosidase production were observed when A. ochraceus was cultivated with $1 \%$ wheat bran added of $10 \%$ wheat straw liquor (produced after 15 min of hydrothermal treatment) as carbon source. This substrate was more favorable when compared with xylan, wheat bran, and wheat straw autohydrolysis liquor used separately. The application of this substrate mixture in a stirred tank bioreactor indicated the possibility of scaling up the process to commercial production.
\end{abstract}

Keywords Xylanase $\beta \beta$-xylosidase $\cdot$ Wheat bran . Wheat straw autohydrolysis liquor . Bioreactor

M. Michelin • D. S. Ruzene · D. P. Silva • A. A. Vicente · J. A. Teixeira IBB-Institute for Biotechnology and Bioengineering, Centre of Biological Engineering, University of Minho, Campus Gualtar, 4710-057 Braga, Portugal

M. Michelin • M. L. T. M. Polizeli • J. A. Jorge $\cdot$ H. F. Terenzi

Department of Biology, Faculty of Philosophy, Sciences and Letters of Ribeirão Preto, University of São Paulo, 14040-901 Ribeirão Preto, São Paulo, Brazil

D. S. Ruzene • D. P. Silva $(\bowtie)$

Institute of Technology and Research, University Tiradentes, Campus Farolândia, 49032-490 Aracaju, Sergipe, Brazil

e-mail: silvadp@hotmail.com 


\section{Introduction}

Lignocellulosic materials (LCM) are heterogeneous and present a complex chemical nature. Their integral benefit can be achieved by chemical fractionation, following the "biomass refining" philosophy $[1,2]$ based on the selective separation of the main components to yield a variety of high added-value bioproducts. This operational method allows a complete utilization of the raw materials by means of sequential treatments. In this field, autohydrolysis (in which the feedstock and water are the only reagents) causes a selective solubilization of hemicelluloses, leading to liquors containing sugar oligomers, sugars and sugar decomposition products, and to a solid phase enriched in cellulose and lignin, which can be subjected to further processing $[3,4]$.

The most abundant hemicellulose is xylan, made up of xylose units. Xylans represent an immense resource of biopolymers for practical applications, accounting for $25-35 \%$ of the dry biomass of woody tissues of dicots and lignified tissues of monocots, and occur up to $50 \%$ in some tissues of cereal grains. The structure of xylans depends on the source considered. The most common xylans are made up of a main backbone of xylose linked by $\beta-1,4$ bonds, where the structural units are often substituted at positions C2 or C3 with arabinofuranosyl, 4- $O$-methylglucuronic acid, acetyl or phenolic substituents [2, 5].

Xylanases play a key role in xylan hydrolysis to xylooligosaccharides. Microbial xylanases mainly include xylanase or endoxylanase (1,4- $\beta$-D-xylan xylanohydrolase, E.C. 3.2.1.8) that cleaves $\beta$-1,4-linked xylan backbone producing xylooligosaccharides, and $\beta$ xylosidase (1,4- $\beta$-xylan xylohydrolase, E.C. 3.2.1.37) that hydrolyses xylooligosaccharides and xylobiose releasing xylose [6-9]. From a commercial viewpoint, xylanases are an important group of carbohydrolases and have a worldwide market of around \$200 million each year $[8,10]$. Xylanases have been widely applied in food, animal feed, bioconversion, textile, and in paper and pulp industries $[8,11]$.

The successful use of a microbial enzyme on an industrial scale will depend on the viability of its large-scale production. Xylanase is an industrially useful enzyme, and investigations of the optimal conditions and the effects of scale-up procedures for its optimal production are thus important [12]. Thus, the aim of the present work was to investigate the xylanase production by Aspergillus ochraceus using a low-cost material (such as wheat straw autohydrolysis liquor and/or wheat bran) as substrate and the possible application of this substrate on production of xylanolytic enzymes in a stirred tank bioreactor (STB).

\section{Materials and Methods}

\section{Materials}

Wheat residues (wheat bran and wheat straw) were kindly supplied by a local farmer (Quinta dos Ingleses, Caide, Portugal). The wheat bran was stored at room temperature and the wheat straw (material for autohydrolysis treatment), after being dried at $40{ }^{\circ} \mathrm{C}$ in an oven for $12 \mathrm{~h}$, was cut into small pieces $(1-3 \mathrm{~cm})$ and subsequently milled in a knives mill to pass through a 1.0$\mathrm{mm}$ sieve, and stored at room temperature. All chemicals used were of analytical grade.

\section{Extraction of Hemicellulose}

Milled wheat straw samples and water were mixed in a closed and pressurized vessel in order to obtain a solid/liquid ratio of $1: 10(w / v)$. The system was heated to $200{ }^{\circ} \mathrm{C}$ for 5,15 , 
30 , or $50 \mathrm{~min}$. The liquid phase or liquor (hemicelluloses-rich fraction) was separated from the solids by filtration using Whatman no. 1 filter paper, and then used as liquid substrate. Figure 1 shows a scheme for the production of wheat straw autohydrolysis liquor, that is, the extraction of hemicelluloses from ground wheat straw.

Microorganism

The microorganism used in this work was a fungal strain $A$. ochraceus. It was isolated from decomposing fruits and leafs, in the Ribeirão Preto region, SP, Brazil, and deposited at the

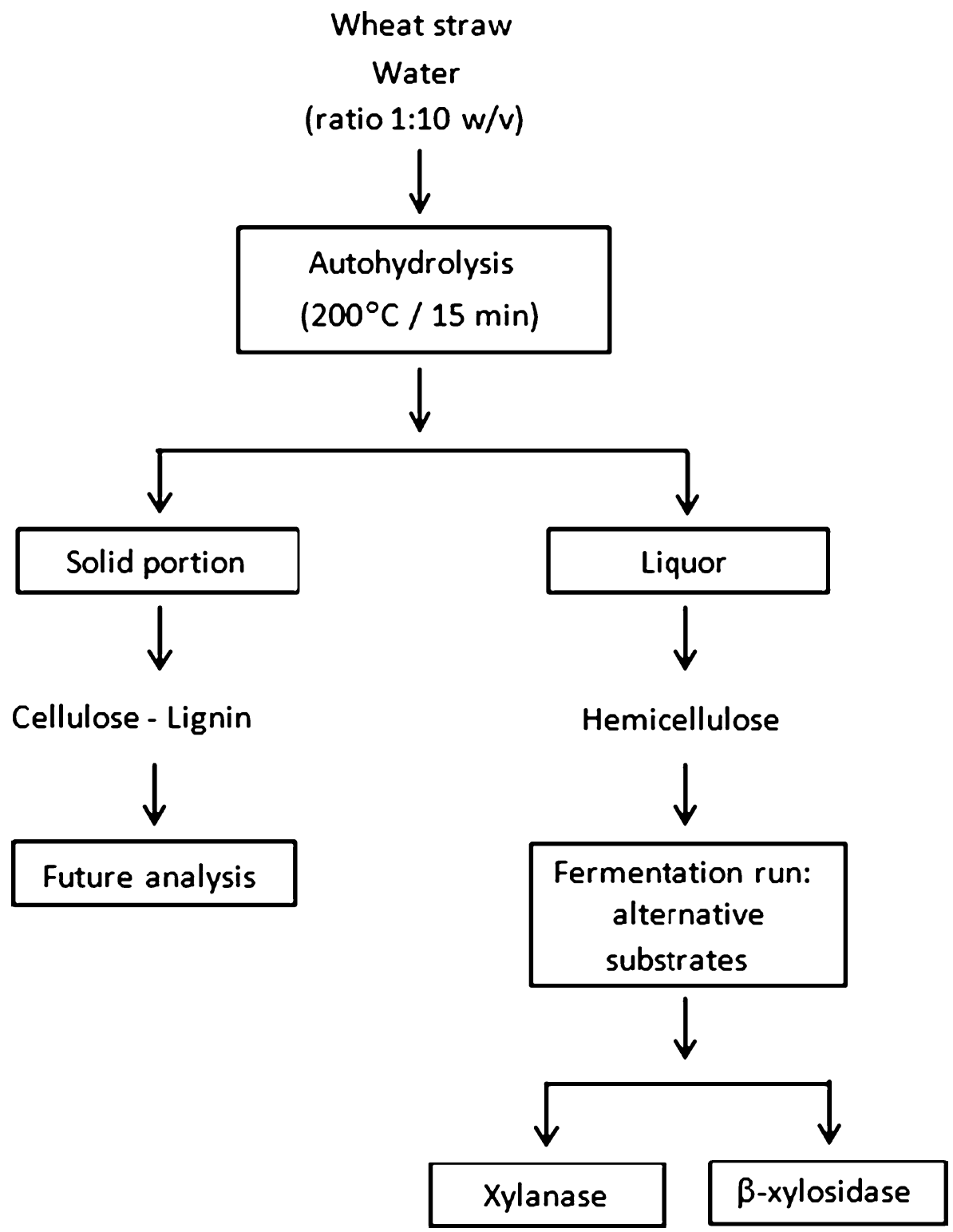

Fig. 1 Scheme for extraction of hemicelluloses from ground wheat straw 
certified Mycology Culture Collection URM from Federal University of Pernambuco (Recife, Brazil). This fungus was maintained on slants of PDA medium (Difco Laboratories, Becton, Dickinson and Co., Sparks, MD, USA), at $4{ }^{\circ} \mathrm{C}$.

\section{Cultivation Conditions}

Conidia from 7-day-old cultures, with cell concentration of $2 \times 10^{8}$ cells $\mathrm{ml}^{-1}$, were inoculated into 250-ml Erlenmeyer flasks containing $50 \mathrm{ml}$ of the liquid medium described by Adams [13], $\mathrm{pH}$ 6.0, containing as carbon source: 1\% $(w / v)$ birchwood xylan (Sigma Co., St. Louis, MO, USA), or $1 \%(w / v)$ wheat bran, or $100 \%(v / v)$ wheat straw autohydrolysis liquor, or a combination of wheat bran and wheat straw autohydrolysis liquor in different concentrations, as specified in each experiment. The cultures were incubated at $30{ }^{\circ} \mathrm{C}$, at $100 \mathrm{rpm}$, for up to 7 days. During fermentation experiments, samples were taken every $24 \mathrm{~h}$, and the mycelia and residues were removed by centrifugation at $10,000 \times \mathrm{g}$ for $15 \mathrm{~min}$. The supernatants were used as the source of crude extracellular xylanase and $\beta$-xylosidase.

\section{Bioreactor Operation Conditions}

A STB with 2-L capacity (Bioengineering AG CH-8636 Wald, Switzerland) equipped with automatic monitoring and control facilities for temperature, $\mathrm{pH}$, agitation, and aeration was used for enzyme production with $A$. ochraceus. The fungal spores $\left(2 \times 10^{8} \mathrm{cells} \mathrm{m}^{-1}\right)$ were inoculated in Adams medium [13], containing 1\%(w/v) wheat bran and $10 \%(v / v)$ wheat straw liquor, after $15 \mathrm{~min}$ of hydrolysis. The working volume was $1 \mathrm{~L}$, the temperature was kept at $30{ }^{\circ} \mathrm{C}$, the agitation rate was maintained at $300 \mathrm{rpm}$, and the aeration rate was adjusted to $1 \mathrm{vvm}\left(1 \mathrm{Lmin}^{-1}\right)$. The $\mathrm{pH}$ was monitored during the whole fermentation period. The fermentation medium was filtrated using Whatman no. 1 filter paper and used as source of crude extracellular xylanase and $\beta$-xylosidase.

\section{Enzymatic Assays}

Xylanase activity was assayed using birchwood xylan as substrate. Reaction mixtures contained $0.2 \mathrm{ml}$ enzyme and $0.2 \mathrm{ml} 1 \%(w / v)$ xylan solution in citrate-phosphate buffer, $\mathrm{pH}$ 6.0. The mixture was incubated at $60{ }^{\circ} \mathrm{C}$, and after $10 \mathrm{~min}$ the released reducing sugars were estimated with DNS, using xylose as standard [14]. $\beta$-Xylosidase activity was assayed using $p$-nitrophenyl- $\beta$-D-xylopyranoside (PNP-xyl) as substrate. Reaction mixtures contained $0.2 \mathrm{ml}$ enzyme, $0.15 \mathrm{ml}$ citrate-phosphate buffer, $\mathrm{pH} 4.5$, and $0.05 \mathrm{ml} 0.25 \%(w / v)$ PNP-xyl in distilled water. The mixture was incubated at $70{ }^{\circ} \mathrm{C}$, and after $10 \mathrm{~min}$ the released $p$-nitrophenolate was estimated with saturated sodium tetraborate solution, using $p$-nitrophenol as standard [15].

One unit of enzymatic activity $(U)$ was defined as the amount of enzyme that released $1 \mu \mathrm{mol}$ of product per minute under the conditions of the assay. Total activity $\left(U_{\text {total }}\right)$ was calculated by multiplying the units (micromoles per minute) by the total volume of enzymatic extract.

\section{Experimental Design}

Response surface methodology and factorial design were used to verify the influence of the independent variables wheat bran $\left(X_{1}\right)$ and wheat straw liquor $\left(X_{2}\right)$ obtained after 15 min of 
hydrothermal treatment at $200{ }^{\circ} \mathrm{C}$ in the synthesis of xylanase and $\beta$-xylosidase. The $2^{2}$ factorial design was elaborated with three repetitions in the central point (0), in a total of seven experiments. The independent variables were codified by using:

$$
X_{1}=\frac{(\mathrm{WB}-0.75)}{0.25} \quad X_{2}=\frac{(\mathrm{WSL}-6)}{4}
$$

where WB is the wheat bran concentration and WSL is the wheat straw liquor volume.

The levels used to codify the independent variables are present in Table 1. Xylanase and $\beta$-xylosidase activities were evaluated as variable of response (dependent). STATISTICA 8 software (Stat soft Inc., USA) was used for ANOVA statistical and graphical analysis, and the response surface methodology was applied only to those factors displaying a significance higher than $5 \%$.

\section{Results and Discussion}

Wheat Straw Autohydrolysis Liquor: Xylanase and $\beta$-Xylosidase Production

It is well known that hemicelluloses, especially xylan from various sources, are excellent inductors for xylanase production. Wheat bran is an agricultural waste that is most often included in nutrient media for microbial xylanase production. It is characterized by an indefinite composition, depending on the climate and agro-technical conditions [16].

Previous studies showed that wheat bran was the most favorable agricultural residue to xylanase production by $A$. ochraceus [17]; however, other studies also showed that wheat bran particles must be decomposed to soluble compounds to allow their use by the fungus, due to difficulties of working with insoluble substrates in aerated media [18]. Thus, in order to improve the production of xylanolytic enzymes and to facilitate the future conduction of the process in a bioreactor, wheat straw autohydrolysis liquor was added to the cultivation medium. The hydrothermal treatment of xylan-containing LCM breaks the hemicellulosic chain by the hydrolytic action of hydronium ions (generated from water autoionization and from in situ generated organic acids), yielding soluble products (mainly oligosaccharides) that can be assimilated more easily by the microorganism.

According to Fig. 2a, the best conditions (highest xylanase activity) for xylanase production were observed when the microorganism was cultivated with a mixture of $1 \%$ $(w / v)$ wheat bran and $10 \%(v / v)$ wheat straw autohydrolysis liquor after $15 \mathrm{~min}$ of hydrothermal treatment ( $600 U_{\text {total }} ; 96-168 \mathrm{~h}$ cultivation). The xylanase activity obtained from the fermentation with the mixture of wheat bran and wheat straw liquor with $5 \mathrm{~min}$ of hydrothermal treatment (second best option) was $20 \%$ lower than that obtained for the best option. The use of $100 \%(v / v)$ liquor did not present satisfactory results (the best conditions allowed to achieve at least 2.5 times higher xylanase activity).

Table 1 Values of coded independent variables

\begin{tabular}{llll}
\hline Independent variables (\%) & \multicolumn{2}{l}{ Levels } \\
\cline { 2 - 4 } & -1 & 0 & 1 \\
\hline$X_{1}$-Wheat bran & 0.50 & 0.75 & 1.0 \\
$X_{2}$-Wheat straw autohydrolysis liquor & 2.0 & 6.0 & 10 \\
\hline
\end{tabular}


Fig. 2 Xylanase and

$\beta$-xylosidase production by $A$. ochraceus using the wheat straw autohydrolysis liquor after several times of hydrothermal treatment. $1 \%(w / v)$ wheat bran plus $10 \%$ $(v / v)$ wheat straw autohydrolysis liquor after hydrothermal treatment of 5 (black square), 15 (black circle), 30 (black triangle), and 50 min (black diamond); and $100 \%(v / v)$ wheat straw autohydrolysis liquor after hydrothermal treatment of 5 (open square), 15 (open circle), 30 (open triangle), and $50 \mathrm{~min}$ (open diamond). The microorganism was cultivated in Adams medium, at $30{ }^{\circ} \mathrm{C}$, $100 \mathrm{rpm}$, for 7 days. Each point represents the mean activity determined in triplicate. The standard deviation was less than $\pm 5 \%$ for all values
A

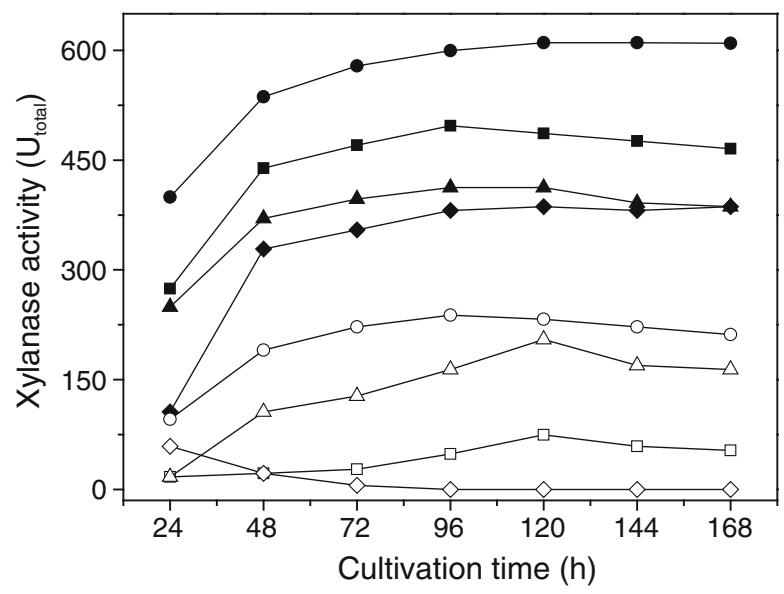

B

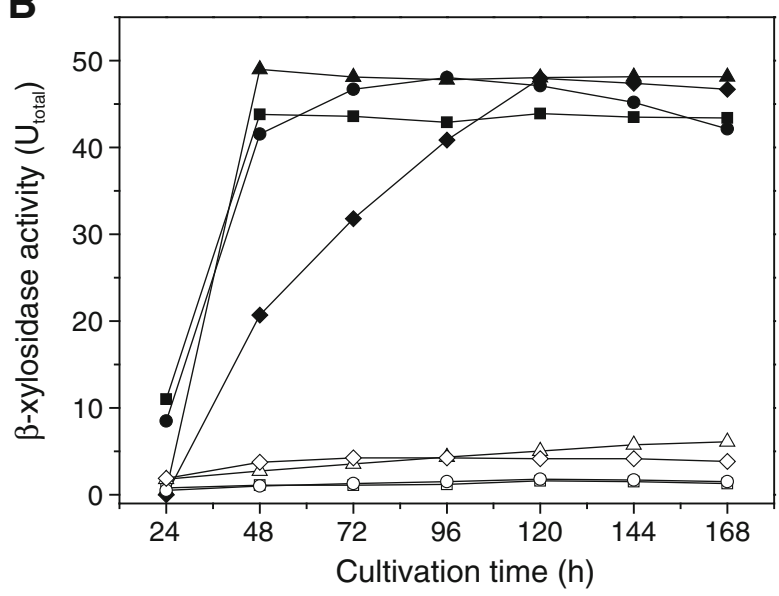

In relation to $\beta$-xylosidase activity, the highest enzymatic activity levels were obtained with the mixture of wheat bran and wheat straw liquor obtained with 15 and $30 \mathrm{~min}$ of autohydrolysis, being the other mixtures also excellent inducers. However, the liquors used alone did not present satisfactory results (Fig. 2b).

Xylan is made up of fast-reacting and slow-reacting fractions, which are decomposed into high molecular weight xylooligosaccharides. When the hydrolytic degradation proceeds, the high molecular weight xylooligosaccharides are converted into low molecular weight oligomers, xylose, and furfural/hydroxymethylfurfural (HMF) in subsequent reactions [19].

According to some authors, HMF concentrations higher than $1 \mathrm{gL}^{-1}$ are reported as inhibitory to microbial metabolism [20, 21], which may explain the low enzyme production, or even the absence of production observed when the liquor with $50 \mathrm{~min}$ autohydrolysis was used as substrate, since furfural/HMF concentration increases with the 
increase in reaction time. These toxic compounds can be divided into four groups: (a) products of sugar degradation including furfural and hydroxymethylfurfural (HMF), (b) products of lignin degradation, including a variety of aromatic compounds, (c) substances released from the lignocellulosic structure during the hydrolytic process, such as acetic acid and wood extractives (acids resin, tannic acid, and terpenes), and (d) metals from corrosion of hydrolysis equipment, in particular iron ions, chromium, nickel, and copper [22]. Therefore, xylanase and $\beta$-xylosidase production by bioconversion of the hydrolysate of the hemicellulose fraction contained in LCM is dependent on the microorganism's productive capacity and also on its tolerance to inhibitory effects due to several toxic compounds contained in those hydrolysates.

\section{Response Surface Methodology}

Response surface methodology has been broadly applied in the search for optimum conditions in multivariable systems and in the analysis of the interaction of variables [23-25]. In this work, the highest xylanase and $\beta$-xylosidase production by A. ochraceus occurred around day 5 , and the production rate exceeded that of most other xylanase-producing species [26]. Thus, the benefit factor was fixed at day 5, and wheat bran concentration $\left(X_{1}\right)$ and wheat straw liquor volume $\left(X_{2}\right)$ produced after $15 \mathrm{~min}$ of hydrothermal treatment (the best time of hydrothermal treatment standardized previously, Fig. 2) were chosen as variables in a twolevel design assay. The results of each point based in this experimental design are shown in Table 2, and the higher xylanase and $\beta$-xylosidase activities were detected with the mixture of $1 \%(w / v)$ wheat bran and $10 \%(v / v)$ wheat straw autohydrolysis liquor, the same concentration used in previous experiment (Fig. 2).

However, after ANOVA variance analysis of $X_{1}$ and $X_{2}$ for xylanase and $\beta$-xylosidase activities, the results show that there is no significant effect $(p \leq 0.05)$ of those two factors in xylanase production for the concentrations tested. However, $X_{1}$ and $X_{1} \times X_{2}$ interactions were found to be significant $(p>0.05)$ for $\beta$-xylosidase activity, presenting a good performance in the $F$ test.

The determination coefficient $\left(R^{2}=0.95\right)$ implies that $95 \%$ of the sample variation for $\beta$ xylosidase production is attributable to the independent variables, and that only $5 \%$ of the total variation cannot be explained by the model. The factors' significance was adjusted according to a linear model, and the graphical representation provides a method for visualizing the relationship between the response and the interaction between the tested variables in order to determine the optimum conditions. The surface plot of Fig. 3 shows

Table 2 Matrix of the factorial design with coded independent variables

\begin{tabular}{lccccc}
\hline \multirow{2}{*}{ Run number } & \multicolumn{2}{l}{ Coded levels } & & \multicolumn{2}{l}{ Y Activity $\left(U_{\text {total }}\right)$} \\
\cline { 2 - 3 } \cline { 5 - 6 } & $X_{1}$ & $X_{2}$ & & Xylanase & $\beta$-xylosidase \\
\hline 1 & -1 & -1 & & 460.0 & 38.60 \\
2 & -1 & +1 & & 359.5 & 24.80 \\
3 & +1 & -1 & & 484.0 & 40.10 \\
4 & +1 & +1 & & 550.0 & 45.70 \\
$5^{\mathrm{a}}$ & 0 & 0 & & 495.0 & 37.60 \\
$6^{\mathrm{a}}$ & 0 & 0 & & 416.0 & 41.00 \\
$7^{\mathrm{a}}$ & 0 & 0 & 426.5 & 39.40 \\
\hline
\end{tabular}




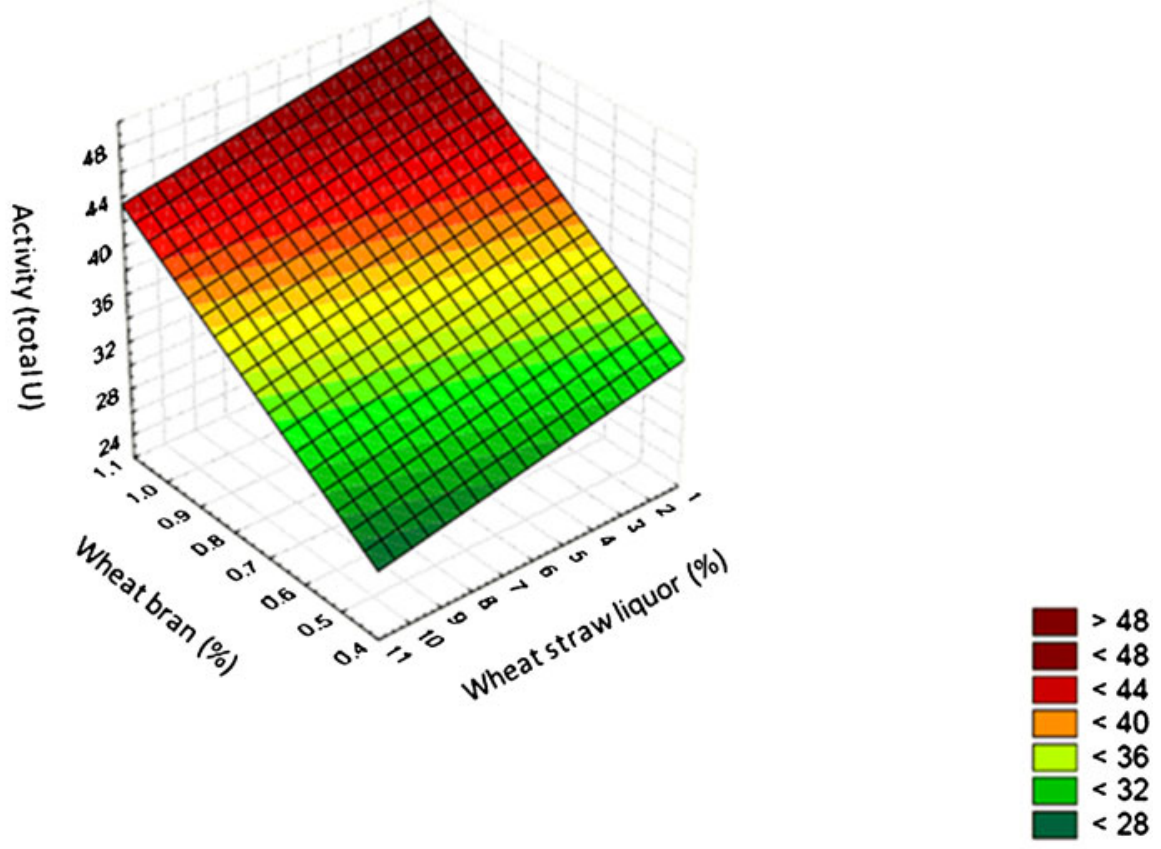

Fig. 3 Response surface plot of the combined effect of wheat bran and wheat straw autohydrolysis liquor produced after $15 \mathrm{~min}$ of hydrothermal treatment on $\beta$-xylosidase production by A. ochraceus

the effect of wheat bran and wheat straw liquor concentrations on $\beta$-xylosidase production. It can be seen that the microorganism needed higher concentrations of wheat bran and lower concentrations of wheat straw autohydrolysis liquor (15 min hydrothermal treatment) for a high $\beta$-xylosidase synthesis.

\section{Comparison of Carbon Sources in Xylanase Production}

The use of purified xylan as substrate to induce xylanase synthesis is costly for large-scale production, whereas LCM can be used as cost-effective substrates for xylanase production $[27,28]$. Thus, cultivation was performed using xylan, wheat bran, the mixture of wheat bran and wheat straw autohydrolysis liquor after 15 min of hydrothermal treatment (the one presenting the best results in terms of enzyme production) and only wheat straw autohydrolysis liquor, in order to compare the enzymatic production when using these substrates.

The xylanase production obtained with a mixture of $1 \%(w / v)$ wheat bran and $10 \%(v / v)$ wheat straw liquor (15 min of hydrothermal treatment) was $20 \%$ higher than that obtained with birchwood xylan (144-168 h cultivation), which is a very significant result if this process can be applied at industrial scale because of the high cost of xylan. The isolated use of wheat bran as inducer for xylanase production rendered around $70 \%$ of the production obtained with birchwood xylan, while the use of $100 \%$ wheat straw autohydrolysis liquor as carbon source corresponded to $45 \%$ of the xylanase activity observed with the xylan during the cultivation period of 144-168 h (Fig. 4a). 
Fig. 4 Xylanase and

$\beta$-xylosidase production by $A$. ochraceus using the carbon sources: $1 \%(w / v)$ birchwood xylan (black square), $1 \%(w / v)$ wheat bran (open square), mixture of $1 \%$ $(w / v)$ wheat bran plus $10 \%(v / v)$ wheat straw autohydrolysis liquor after 15 min of hydrothermal treatment (black circle), and 100\% $(v / v)$ wheat straw autohydrolysis liquor after $15 \mathrm{~min}$ of hydrothermal treatment (open circle). The microorganism was cultivated in Adams medium, at $30^{\circ} \mathrm{C}$, $100 \mathrm{rpm}$, for 7 days. Each point represents the mean activity determined in triplicate. The standard deviation was less than $\pm 5 \%$ for all values
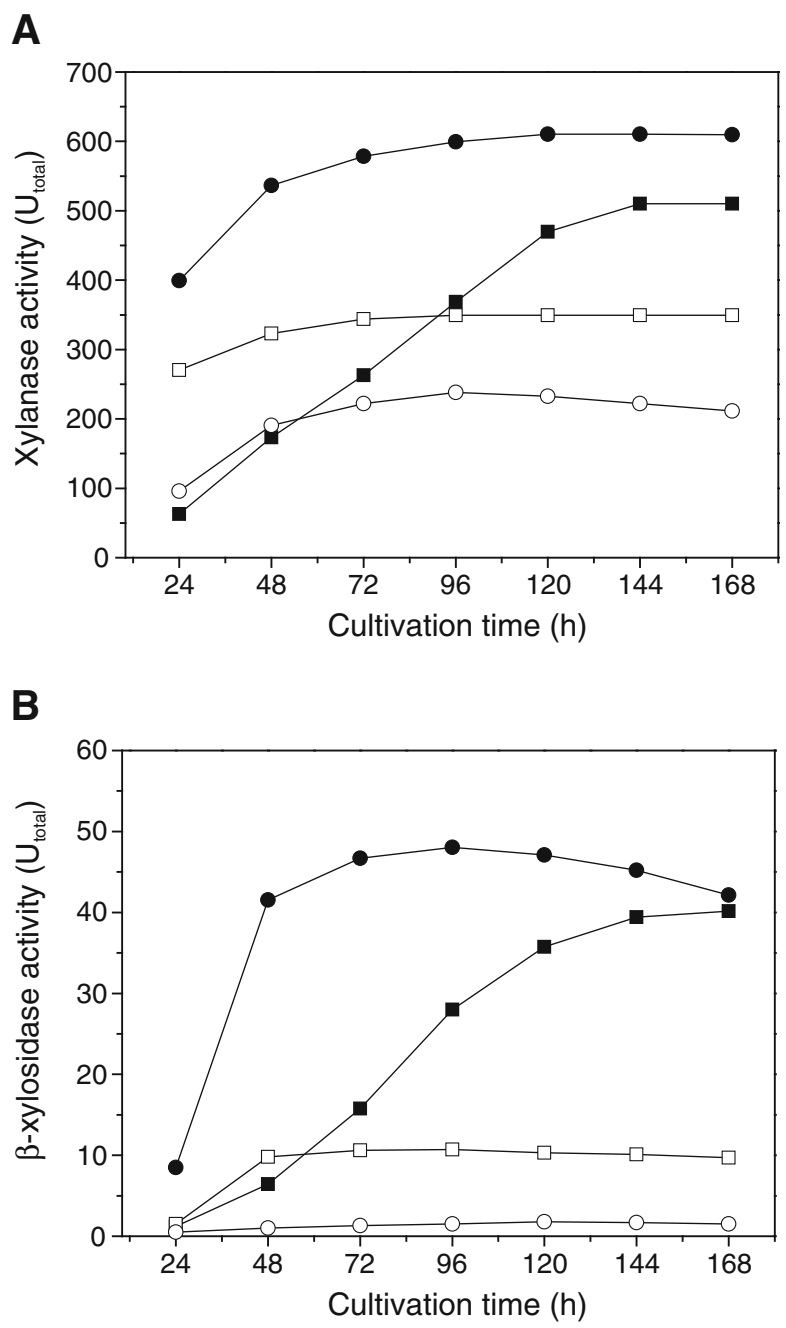

In relation to $\beta$-xylosidase production, the mixture of wheat bran and wheat straw liquor (15 min of hydrothermal treatment) reached maximum activity levels with $96 \mathrm{~h}$ cultivation; this was also $20 \%$ higher than that obtained with birchwood xylan during $168 \mathrm{~h}$ cultivation. The use of wheat bran alone rendered approximately $25 \%$ activity observed with the xylan, and the use of the liquor as the only carbon source was not suitable to $\beta$-xylosidase production-only around $5 \%$ of the activity verified with birchwood xylan in the cultivation period of $168 \mathrm{~h}$ (Fig. 4b). Moreover, the shorter fermentation time obtained for the mixture of wheat bran and wheat straw liquor renders the process more viable, once longer production times also signify higher production costs. In fact, the highest levels of xylanase and $\beta$-xylosidase production were observed after $48 \mathrm{~h}$ of fermentation with this mixture, obtaining a maximum production between 96 and $120 \mathrm{~h}$ of fermentation. When xylan was used as carbon source, a significant induction of xylanolytic enzymes production was only observed between 144 and $168 \mathrm{~h}$ of fermentation (Fig. 4a, b). 


\section{Production in STB}

The achievement of high xylanase activity in the inclusion of these plant wastes in nutrient medium composition has an exceptionally important economical significance in xylanase production. A tentative large-scale production was performed in STB, as described in "Materials and Methods" section. The agitation rate was chosen according to Siedenberg et al. [29], where the highest level of xylanase production by Aspergillus awamori was reported at $300 \mathrm{rpm}$. While the aeration rate was selected according to Hoq et al. [30] and Reddy et al. [12] who reported the highest xylanase activity by Thermomyces lanuginosus at $1 \mathrm{vvm}$.

Figure 5 shows the fermentation course, where it is shown that xylanase production $\left(4.530 U_{\text {total }}\right)$ was not maximal after $168 \mathrm{~h}$ of fermentation, while the maximal $\beta$-xylosidase production $\left(57 U_{\text {total }}\right)$ was verified within $144-168 \mathrm{~h}$ of fermentation. Therefore, in the STB used, the time for enzymatic production was higher than the one observed in Erlenmeyer flasks with the mixture of wheat bran and wheat straw autohydrolysis liquor; besides, the production rate (expressed in units per hour) was lesser.

In bioreactor submerged cultures, xylanase production by filamentous fungi may also be affected by shear stress, which is related to the agitation rate. The high viscosities and nonNewtonian behavior of culture broths of filamentous fungi often necessitate the use of high agitation rates to provide adequate mixing and oxygen transfer. However, mycelial damage due to high shear stress limits the usable range of stirrer speed and consequently the volumetric biomass and enzyme productivity of the culture. Several papers reported on the effects of agitation rate in combination with the aeration rate and dissolved oxygen tension [30-35].

These results suggest the complexity of the fermentation process in STB and the necessity to optimize some conditions, as agitation and aeration rates. It is also needed to consider the usage of alternative bioreactors, such as the airlift or bubble column, which have a lower shear stress for application in e.g. xylanase production.

\section{Conclusion}

The development of a low-cost process for xylanase production is very attractive for industrial biotechnology, and agro-industrial residues are interesting for this purpose due to

Fig. 5 Performance of $A$. ochraceus during fermentation in STB for xylanase (black square) and $\beta$ xylosidase (open square) production using the mixture of $1 \%(w / v)$ wheat bran plus $10 \%(v / v)$ wheat straw autohydrolysis liquor after 15 min of autohydrolysis treatment. The microorganism was cultivated at $30{ }^{\circ} \mathrm{C}, 300 \mathrm{rpm}$, $1 \mathrm{vvm}$. Each point represents the mean activity determined in triplicate. The standard deviation was less than $\pm 5 \%$ for all values

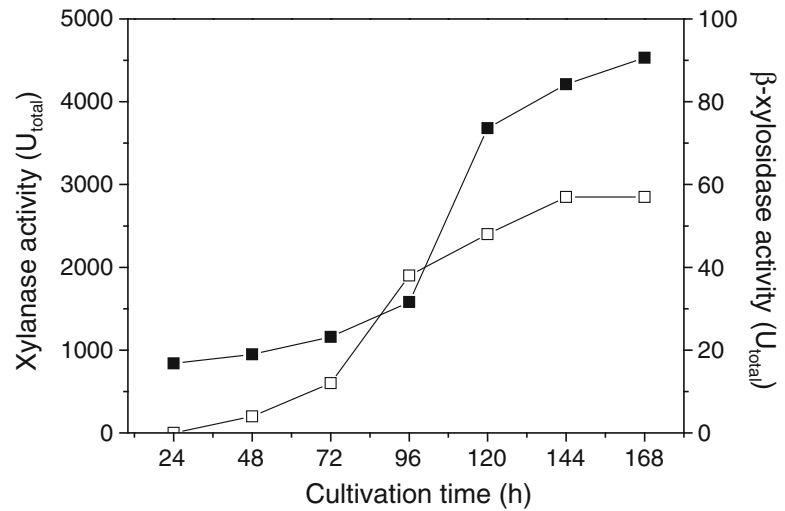


their high availability associated with their low cost. However, these materials usually need pretreatments to become more susceptible to microorganism action. The wheat straw autohydrolysis treatment to obtain hemicelluloses-rich liquor to be used as adjunct in xylanase and $\beta$-xylosidase production for $A$. ochraceus was very promising since with the use of $1 \%(\mathrm{w} / \mathrm{v})$ wheat bran plus $10 \%(\mathrm{v} / \mathrm{v})$ wheat straw liquor (produced after $15 \mathrm{~min}$ of hydrothermal treatment) as carbon source, the xylanase production was around $20 \%$ higher than birchwood xylan (an expensive substrate that is considered as "model" for xylanase production) and $45 \%$ higher than wheat bran. In relation to $\beta$-xylosidase induction, enzymatic levels higher than xylan and wheat bran were also observed with this mixture. Moreover, the production time with $1 \%(\mathrm{w} / \mathrm{v})$ wheat bran plus $10 \%(\mathrm{v} / \mathrm{v})$ wheat straw liquor (15 min autohydrolysis) was shorter than xylan, which is an advantage in industrial process. In conclusion, the use of these treated residues to xylanolytic production in STB showed the possibility of scaling up, but further experiments must be performed in order to optimize the process.

Acknowledgments This work was supported by Fundação de Amparo à Pesquisa do Estado de São Paulo (FAPESP/Brazil), Conselho Nacional de Desenvolvimento Científico e Tecnológico (CNPq/Brazil), National System for Research on Biodiversity (SISBIOTA-Brazil, CNPq 563260/2010-6/FAPESP no. 2010/52322-3), and Fundação para a Ciência e a Tecnologia (FCT/Portugal).

\section{References}

1. Myerly, R. C., Nicholson, M. D., Katzen, R., \& Taylor, J. M. (1981). Chemtech, 11, 186-192.

2. Moure, A., Gullón, P., Domínguez, H., \& Parajó, J. C. (2006). Process Biochemistry, 41, 1913-1923.

3. Garrote, G., Domínguez, H., \& Parajó, J. C. (2002). Journal of Food Engineering, 52, 211-218.

4. Garrote, G., Falqué, E., Domínguez, H., \& Parajó, J. C. (2007). Bioresource Technology, 98, 1951-1957.

5. Ebringerova, A., \& Heinze, T. (2000). Macromolecular Rapid Communications, 21, 542-556.

6. Abdel-Sater, M. A., \& El-Said, A. H. M. (2001). International Biodeterioration and Biodegradation, 47, $15-21$.

7. Polizeli, M. L. T. M., Rizzatti, A. C. S., Monti, R., Terenzi, H. F., Jorge, J. A., \& Amorim, D. S. (2005). Applied Microbiology and Biotechnology, 67, 577-591.

8. Liu, C., Sun, Z.-T., Du, J.-H., \& Wang, J. (2008). Journal of Industrial Microbiology and Biotechnology, 35(7), 703-711.

9. Polizeli, M. L. T. M. (2009). Properties and commercial applications of xylanases from fungi. In M. Rai (Ed.), Advances in fungal biotechnology (Vol. 1, pp. 82-108). New Delhi: IK International Publisher.

10. Katapodis, P., Christakopoulou, V., Kekos, D., \& Christakopoulou, P. (2007). Biochemical Engineering Journal, 35, 136-141.

11. Subramanyan, S., \& Prema, P. (2002). Critical Reviews in Biotechnology, 22, 33-64.

12. Reddy, V., Reddy, P., Pillay, B., \& Singh, S. (2002). Process Biochemistry, 37, 1221-1228.

13. Adams, P. R. (1990). Mycopathologia, 112, 35-37.

14. Miller, G. H. (1959). Analytical Chemistry, 31, 426-429.

15. Kersters-Hilderson, H., Claeyssens, M., Doorslaer, E. V., Saman, E., \& Bruyne, C. K. (1982). Methods in Enzymology, 83, 631-639.

16. Techapun, C., Poosaran, N., Watanabe, M., \& Sasaki, K. (2003). Process Biochemistry, 38, 1327-1340.

17. Michelin, M., Peixoto-Nogueira, S. C., Betini, J. H. A., Silva, T. M., Jorge, J. A., Terenzi, H. F., et al. (2010). Bioprocess Biosyst Engineer, 33, 813-821.

18. Michelin, M., Polizeli, M. L. T. M., Silva, D. P., Ruzene, D. S., Vicente, A. A., Jorge, J. A., Terenzi, H. F., \& Teixeira, J. A. (2011). Journal of Industrial Microbiology and Biotechnology. doi:10.1007/s10295-011-0987-7.

19. Parajó, J. C., Garrote, G., Cruz, J. M., \& Dominguez, H. (2004). Trends in Food Science and Technology, 15, 115-120.

20. Sanchez, Z. B., \& Bautista, J. (1988). Enzyme and Microbial Technology, 10, 315-318. 
21. Felipe, M. G. A., Mancilha, I. M., Vitolo, M., Roberto, I. C., Silva, S. S., \& Rosa, S. A. M. (1993). Arquivos de Biologia e Tecnologia, 36, 103-114.

22. Olsson, L., \& Hahn-Hagerdal, B. (1996). Enzyme and Microbial Technology, 18, 312-331.

23. Kalathenos, P., Baranyi, J., Sutherland, J. P., \& Roberts, T. A. (1995). International Journal of Food Microbiology, 25, 63-74.

24. Moyo, S., Gashe, B. A., Collison, E. K., \& Mpuchane, S. (2003). International Journal of Food Microbiology, 85, 87-100.

25. Fang, H. Y., Chang, S. M., Hsieh, M. C., \& Fang, T. J. (2007). Journal of Molecular Catalysis B: Enzymatic, 49, 36-42.

26. Coelho, G. D., \& Carmona, E. C. (2003). Journal of Basic Microbiology, 43(4), 269-277.

27. Haltrich, D., Nidetsky, B., Kulbe, K. D., Steiner, W., \& Zupancic, S. (1996). Bioresource Technology, 58, $137-161$.

28. Beg, Q. K., Bhushan, B., Kapoor, M., \& Hoondal, G. S. (2000). Enzyme and Microbial Technology, 27, $459-466$.

29. Siedenberg, D., Gerlach, S. R., Czwalinna, A., Schugerl, K., Giuseppin, M. L. F., \& Hunik, J. (1997). Journal of Biotechnology, 56, 205-216.

30. Hoq, M. M., Hempel, C., \& Deckwer, W.-D. (1994). Journal of Biotechnology, 37, 49-59.

31. Palma, M. B., Milagres, A. M. F., Prata, A. M. R., \& de Mancilha, I. M. (1996). Process Biochemistry, 31, 141-145.

32. Singh, S., du Preez, J. C., Pillay, B., \& Prior, B. A. (2000). Applied Microbiology and Biotechnology, 54, 698-704.

33. Silva, D. P., Pessoa, A., Jr., Roberto, I. C., \& Vitolo, M. (2001). Applied Biochemistry and Biotechnology, 91-93, 605-613.

34. Techapun, C., Poosaran, N., Watanabe, M., \& Sasaki, K. (2003). Journal of Bioscience and Bioengineering, 95, 298-301.

35. Chipeta, Z. A., du Preez, J. C., \& Christopher, L. (2008). Journal of Industrial Microbiology and Biotechnology, 35(6), 587-594. 